\title{
Correction to: Newborn screening in mucopolysaccharidoses
}

Maria Alice Donati ${ }^{1}$, Elisabetta Pasquini ${ }^{1}$, Marco Spada $^{3}$, Giulia Polo $^{2}$ and Alberto Burlina ${ }^{2^{*}}$

\section{Correction to: Ital J Pediatr \\ https://doi.org/10.1186/s13052-018-0552-3}

The original article [1] contains an unintended omission of a statement of competing interests. As such, the authors would like to declare the following complete statement of competing interests:

\section{Competing interests}

MAD has received speaker honoraria and travel support from Sanofi Genzyme, Biomarin, Shire and Actelion. The pilot project of NBS in Tuscany and Umbria has been partially supported by Sanofi Genzyme. AB has received speaker honoraria and travel support from Sanofi Genzyme, Biomarin, and Actelion. The remaining authors declare that they have no competing interests.

\section{Author details}

${ }^{1}$ Metabolic and Muscular Unit, Regional Reference Centre Expanded Newborn Screening, Meyer Children Hospital, Florence, Italy. ${ }^{2}$ Division of Inherited Metabolic Diseases, Regional Center for Expanded Neonatal Screening, Department of Women and Children's Health, University Hospital of Padova, Via Orus 2/B, 35129 Padova, Italy. ${ }^{3}$ Department of Pediatrics,

Ospedale Regina Margherita, P.zza Polonia, 94, 10126 Torino, Italy.

Received: 28 May 2019 Accepted: 28 May 2019

Published online: 11 June 2019

\section{Reference}

1. Donati MA, et al. Newborn screening in mucopolysaccharidoses. Ital J

Pediatr. 2018;44(Suppl 2):126 https://doi.org/10.1186/s13052-018-0552-3.

\footnotetext{
* Correspondence: alberto.burlina@unipd.it

2Division of Inherited Metabolic Diseases, Regional Center for Expanded Neonatal Screening, Department of Women and Children's Health, University Hospital of Padova, Via Orus 2/B, 35129 Padova, Italy

Full list of author information is available at the end of the article
}

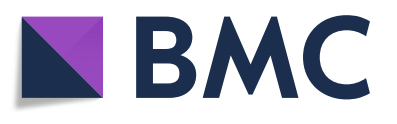

(c) The Author(s). 2019 Open Access This article is distributed under the terms of the Creative Commons Attribution 4.0 International License (http://creativecommons.org/licenses/by/4.0/), which permits unrestricted use, distribution, and reproduction in any medium, provided you give appropriate credit to the original author(s) and the source, provide a link to the Creative Commons license, and indicate if changes were made. The Creative Commons Public Domain Dedication waiver (http://creativecommons.org/publicdomain/zero/1.0/) applies to the data made available in this article, unless otherwise stated. 